\title{
SPOR BILIMLERI VE TEKNOLOJISI YÜKSEKOKULUNDA ÖĞRENIM GÖREN ÖĞRENCILERIN ZAMAN YÖNETIMI DAVRANIŞLARI
}

\author{
Mustafa SUGÖTÜREN ${ }^{1}$ Özgür MÜLAZIMOĞLU BALLI ${ }^{1}$ \\ Hüseyin GÖKÇE ${ }^{1}$
}

Geliş Tarihi:

Kabul Tarihi:

\begin{abstract}
ÖZET
Bu araştırmanın amacı Spor Bilimleri ve Teknolojisi Yüksekokulu’nda (SBTYO) öğrenim gören öğrencilerin zaman yönetimi davranışlarının belirlenmesidir. Bu çalışmaya 61 kadın ( $\bar{X}$ yaş=20.48 SS=1.91) ve 132 erkek ( $\bar{X}$ yaş=22.30 SS=2.03) olmak üzere

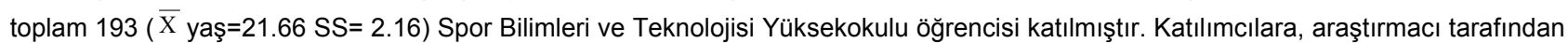
hazırlanan "Genel Bilgi Formu" ve Britton ve Tesser (1991) tarafından geliştirilen ve Türkçe geçerlilik ve güvenilirliği Alay ve Koçak (2002) tarafından yapılan "Zaman Yönetimi Anketi" uygulanmıştır. Verilerin analizinde, tanımlayıcı istatistikler, T testi ve Tek Yönlü Varyans Analizi kullanılıştır. Çalışma sonucunda Spor Bilimleri ve Teknolojisi Yüksekokulu bölümlerinde öğrenim gören öğrencilerin cinsiyete göre Zaman Yönetimi Envanteri "Zaman Harcattırıcılar" alt boyutunda kadınlar lehine anlamlı bir farklılık bulunurken $\left[t_{(211)}=2.61, p<.05\right]$, diğer alt boyutlarda anlamlı bir farklılık bulunamamıştır $(p>0.05)$. Bölümler arasındaki Zaman Yönetimi Davranışları farkını belirlemek için yapılan tek yönlü varyans analizi sonucunda "Zaman Planlaması, Zaman Tutumları ve Zaman Harcattırıcılar" alt boyutlarında anlamlı bir farklılık tespit edilmemiştir $(p>0.05)$. Sınıflar arasındaki farkı belirlemek amacıyla yapılan tek yönlü varyans analizi sonucunda "Zaman Tutumları" $\left[F_{(3-209)}=3.32, p<.05\right]$ alt boyutunda birinci sınıflar lehine anlamlı bir farklılık bulunurken, diğer alt boyut sonuçlarında ise anlamlı bir farklılık bulunamamıştır $(p>0.05)$. Sonuç olarak kadınların erkeklere oranla zaman harcattırıcılar boyutunda ve birinci sınıfların diğer sınıflara oranla zaman tutumları alt boyutunda daha dikkatli oldukları saptanmıştır.
\end{abstract}

Anahtar kelimeler: Spor Bölümü Öğrencileri, Cinsiyet, Zaman Yönetimi

\section{SCHOOL OF SPORTS SCIENCE AND TECHNOLOGY STUDENTS' TIME MANAGEMENT BEHAVIOR}

\begin{abstract}
The aim of the study was to determine the time management behavior of School of Sport Sciences and Technology students'. 61 female $(\bar{X}$ age=20.47 Sd=1.80) and 132 male $(\bar{X}$ age=22.30 Sd=2.03) with total 193 students $(\bar{X}$ age $=21.66 \mathrm{Sd}=2.16)$ were participated to this study. "The General Information Form" prepared by researchers and "Time Management Questionnaire" which was developed by Britton and Tesser (1991) and Turkish validity and the reliability of this questionnaire was done bye Alay and Koçak (2002) were used. The descriptive statistics, Independent Samples T Test and One Way ANOVA were applied for data analyses. The result of the study showed that there was a statistically significant gender differences in the time waster sub dimension of the instrument in the favor of female $\left[t_{(211)}=2.61, p<.05\right]$, on the other hand there was no significant differences of the time attitude and time planning sub scales of the instrument ( $p>0.05$ ). According to departments' time management behavior results of One Way ANOVA, there was no significant differences in the all subscales and total scores $(p>0.05)$. One Way ANOVA was conducted to determine the time management differences in terms of students' class. The results indicated that there was a significant difference of the time attitude sub dimension in the favor of first grade students $\left[F_{(3-209)}=3.32, p<.05\right]$, but there were no significant differences in the other subscales $(p>0.05)$. As a result, it can be said that there was a positive attitude in the time waster subscales for female students and in the of time attitude subscales for 1 . grade students.
\end{abstract}

Key words: Sport Science's Students, Gender, Time Management.

\footnotetext{
${ }^{1}$ Pamukkale Üniversitesi Spor Bilimleri ve Teknolojisi Yüksekokulu
} 


\section{GíRiş}

Son dönemlerde yokluğundan en çok şikâyet edilen konulardan biri de zamandır (1). Teknolojik gelişmeler sayesinde önceden günlerce ya da aylarca sürecek işler, günümüzde çok kısa sürede halledilebilmektedir. Yaşam tarzının bu denli hızlanması, insanlar üzerindeki zaman baskısını daha çok arttırmış, bu sorun insanların zamanlarını etkili ve verimli bir şekilde yönetmelerini gündeme getirmiştir (2). Bu yüzden zaman yönetimi konusu, kişisel gelişim konuları içinde çok önemli hale gelmiştir.

Zaman yönetimi, kişinin özel ve iş hayatında amaçlarına etkili ve verimli bir şekilde ulaşabilmesi için planlama, organize etme ve kontrol etme gibi yönetim fonksiyonlarını kendi faaliyetlerine uygulama sürecidir (3). Zamanı iyi kullanabilmek, insanın kendisine, çalışma hayatına, sosyal hayatına, dinlenme ve eğlenmesine, biyolojik ve fizyolojik intiyaçların karşılanmasına ayırdığı zaman birimleri arasında dengeyi iyi kurabilmesine bağlıdır (4). Zamanı etkili yönetebilmek, kişisel ve örgütsel başarı ve verimlilik için bir gerekliliktir.

Ulusal ve uluslararası yazın incelendiğinde zaman yönetiminin genellikle yönetim bilimleriyle birlikte ele alındığı görülmektedir $(5,6,7,8)$. Bu çalışmalarda işletme başarısı ya da yönetici başarısının zaman yönetimi davranışlarıyla birlikte ele alındığı görülmektedir. Cinsiyet faktörü göz önünde bulundurulduğunda, kadınların erkeklere oranla zaman planlamalarının daha yüksek, zaman harcattırıcılarda ise anlamlı olarak daha düşük puanlara sahip oldukları ortaya çıkmıştır $(9,10,11)$. Ayrıca zaman yönetimi ile kaygı ve stres $(12,13)$ seviyeleri üzerine yapılan araştırmalarda, zaman yönetimi becerisi ile stres ve kaygı seviyeleri arasında ters orantı olduğu görülmektedir. Dinçay (2011), üniversite öğrencilerinin zaman yönetimi becerileri ile fiziksel aktivite seviyeleri arasındaki ilişkiyi incelenmiş, araştırma sonunda zaman harcattırıcılar ve fiziksel aktivite yapma arasında negatif, zamanı planlama arasında pozitif ilişki bulunmuştur (14).

Zaman yönetimi eğitim hayatı için de ayrı bir önem taşımaktadır. Akademik başarı, iş yaşantısına hazırlık ve yetişkin birey olma yolunda zaman yönetimi becerisinin ölçülmesi ile ilgili yayınlarında bir hayli fazla olduğu görülmektedir $(12,13)$. Özellikle üniversite dönemi öğrenciler için, farklı etkinlik bileşenlerinin kesiştiği ve bireylerin gelecekteki yaşamı açısından oldukça önemli bir süreci ifade etmektedir. Üniversite öğrencileri bir yandan yeni arkadaşlıklara, özgürlüklere ve deneyimlere uyum sağlamaya çalışırken, diğer yandan çok daha karışık görevleri tamamlamak ve ilerde sahip olacakları mesleklere ilişkin temel bilgileri öğrenmeye çabalamaktadır (13). Üniversite yaşamının bu karmaşık yapısı zaman yönetimini üniversite dönemi için daha elzem hale getirmektedir (2). Üniversite öğrencileri ve zaman yönetimi ile ilgili çalışmalar ise genellikle akademik başarı üzerine yoğunlaşmıştır $(2,9,10)$. Bu çalışmalarda da zaman yönetimi davranışları yüksek olan öğrencilerin akademik başarılarının daha iyi olduğu ortaya konulmaktadır. Yapılan araştırma sonunda Spor Bilimleri ve Teknolojisi Yüksekokulu (SBTYO) öğrencilerinin zaman yönetimi davranışları ile ilgili herhangi bir çalışmaya rastlanmamıştır.

Bu araştırmanın amacı, Spor Bilimleri ve Teknolojisi Yüksekokulu'nda öğrenim gören öğrencilerin zaman yönetimi davranışlarının cinsiyetlerine, eğitim gördükleri bölümlerine ve öğrenim gördükleri sınıflarına göre zaman yönetimi davranışlarında anlamlı farklılık olup olmadığını incelemektir.

\section{MATARYEL YÖNTEM}

Katılımcılar: Bu araştırmanın evrenini Pamukkale Üniversitesi Spor Bilimleri Teknolojisi Yüksekokuluna bağlı Beden Eğitimi Öğretmenliği, Antrenörlük ve Rekreasyon bölümlerinin 1., 2., 3. ve 4. sınıflarında öğrenim gören toplam 435 kişi oluşturmaktadır. Çalışma grubunu yukarıda belirtilen bölümlerden 61 kadın ( $\bar{X}$ yaş=20.48 SS=1.91) ve 132 erkek ( $\bar{X}$ yaş=22.30 SS=2.03) olmak üzere toplam $193(\bar{X}$ yaş=21.66 SS=2.16) kişi oluşturmaktadır.

Tablo 1. Katılımcıların cinsiyet ve bölümlere göre yüzde ve frekans dağılımları

\begin{tabular}{|l|c|c|c|c|}
\hline \multirow{2}{*}{ Bölüm } & Cinsiyet & $\mathbf{N}$ & $\%$ & \multirow{2}{*}{$\begin{array}{c}\text { Toplam } \\
\text { N }\end{array}$} \\
\hline \multirow{2}{*}{ Rekreasyon } & Erkek & 42 & 60.9 & \multirow{2}{*}{69} \\
\cline { 2 - 4 } & Kadın & 27 & 39.1 & \\
\hline \multirow{2}{*}{ Öğretmenlik } & Erkek & 37 & 61.7 & \multirow{2}{*}{60} \\
\cline { 2 - 4 } & Kadın & 23 & 38.3 & \multirow{2}{*}{64} \\
\cline { 2 - 4 } Antrenörlük & Erkek & 53 & 82.9 & \multirow{2}{*}{193} \\
\cline { 2 - 4 } Toplam & Kadın & 11 & 17.1 & \\
\cline { 2 - 4 } & Erkek & 132 & 65.7 & \\
\hline
\end{tabular}


Veri Toplama Araçları: Araştırmada öğrenci hakkında bazı bilgileri elde edebilmek amacıyla araştırmacılar tarafından hazırlanan "Genel Bilgi Formu" ve Britton ve Tesser (1991) tarafından geliştirilen, Türkçeye uyarlaması ve geçerlilik, güvenilirliği Alay ve Koçak (2002) tarafından yapılan “Zaman Yönetimi Envanteri” (ZYE)” kullanıımıştır.

Genel Bilgi Formu: Katılımcıların yaş, cinsiyet, bölüm ve sınıf bilgilerini elde etmek amacıyla araştırmacılar tarafından hazırlanmıştır.

Zaman Yönetimi Envanteri (ZYE): ZYE üniversite öğrencilerinin zaman yönetimi becerilerini ölçmek amacıyla Britton ve Tesser (1991) tarafından geliştirilmiş, geçerlilik ve güvenilirliği Alay ve Koçak (2002) tarafından yapılmıştır. Türkçeye uyarlanan ölçekte, Temel Bileşenler Faktör Analizi Çözümlemesi yapılmış ve ölçeğin 27 madde ve 3 alt boyutlu olduğu tespit edilmiştir. Ayrıca ölçeğin güvenirliği için yapılan analizde iç güvenirlik (cronbach alpha) katsayısı .87 bulunmuştur. Zaman planlaması", "zaman tutumları" ve "zaman harcattırıcılar" alt boyutlarından oluşan envanter, 5'li likert yapısındadır. Cevaplar her zaman, sık sık, bazen, nadiren, hiç ifadelerinden oluşmaktadır. Bu ifadelere 1 ile 5 arasında puan verilmiştir. ZYE'de zaman planlaması alt boyutu, uzun süreli ve kısa süreli (bir günlük veya haftalık) planlamaları temsil etmekte olup, bir tanesi (16. madde) tersine ifade olmak üzere 16 soru bulunmaktadır. Bu bölümden yüksek puan alan öğrencilerin, zamanını daha iyi kullananlar sınıfında olup zamanlarını harcamada kendilerinin söz sahibi oldukları belirtilmiştir. Zaman tutumları alt boyutu, kişinin zaman yönetimi ile ilgili neler yaptığına yönelik maddeleri içeren 4 tane düz, 3 tane de (2, 6 ve 7.maddeler) tersine ifadeli olmak üzere, toplam 7 sorudan oluşmaktadır. Bu alt boyuttan yüksek puan alan öğrencilerin, zamanlarını iyi yönettikleri, her şeyi uzun zaman aralığında düşündükleri kabul edilmiştir. Diğer alt boyut ise, öğrencilerin zamanı olumsuz yönde harcayan etkinlikler ile ilgili 4 sorudan oluşmaktadır ve bu soruların hepsinde tersine ifade kullanılmıştır. Bundan dolayı bu maddelere "zaman harcattırıcılar" adı verilmiştir. Zaman harcattırıcıların, öğrencileri okul gayelerinden uzaklaştıran her şeyi içine aldığı ifade edilmiştir. Bu üç al boyuttan alınan puanların toplamının, 27'ye bölünmesi, ZYE toplam ortalama puanını vermektedir.

Verilerin Toplanması: Araştırmanın verileri Pamukkale Üniversitesi Spor Bilimleri Teknolojisi Yüksekokulu Müdürlüğünden izin alınarak, 14 Kasım - 25 Kasım 2009 tarihlerinde, dört farklı bölüm öğrencilerine araştırmacılar tarafından uygulanarak toplanmıştır.

Verilerin Analizi: Verilerin analizinde, Bağımsız Gruplarda T-testi (Independent Samples T-testi) ve Tek Yönlü Varyans Analizi (One-Way Anova) kullanılmıştır. Tüm analizler için anlamlııı düzeyi 0.05 olarak alınmıştır.

\section{BULGULAR}

Çalışmaya katılan 193 öğrencinin cinsiyete göre Zaman Yönetimi alt boyut ve toplam puan ortalamaları Tablo 2'de verilmiştir.

Tablo 2 incelendiğinde, ortalama puanlarının 3.23 ile 3.66 arasında değiştiği görülmektedir. Ancak bütün alt boyutlarda, kadın öğrencilere ait ortalama puanların, erkek öğrencilerden yüksek olduğu göze çarpmaktadır.

Katılımcıların, cinsiyete göre Zaman Yönetimi alt boyutları ve toplam puan ortalamaları arasında fark olup olmadığını tespit etmek amacı ile yapılan t-test sonuçlarına göre SBTYO'da öğrenim gören öğrencilerin Zaman Yönetimi Envanterinin Zaman Planlama alt ölçeğinde [t $\left.{ }_{(193)}=1.71, p>.05\right]$ ve Zaman Tutumları alt ölçeğinde [t $\left.(193)=.37, p>.05\right]$ cinsiyete göre anlamlı bir fark görülmemektedir. Fakat Spor bilimlerinde öğrenim gören öğrencilerin cinsiyete göre Zaman Harcattırıcılar alt ölçeğinde ve Genel Ortalama puanda kadın öğrenciler lehine anlamlı bir fark tespit edilmiştir [t $\mathrm{t}_{(193)}=2.48$, $p<.05]$. Kadın öğrencilerin "Zaman Harcattırıcılar" alt boyutundan ve toplam puandan sırasıyla $(\bar{X}=3.66, \bar{X}=3.43)$ erkeklere ( $\overline{\mathrm{X}}=3.39, \overline{\mathrm{X}}=3.30)$ oranla daha yüksek puan aldıkları görülmektedir.

Tablo 2. Katılımcıların cinsiyete göre Zaman Yönetimi alt boyutları ve toplam puan ortalamalarına ait betimsel istatistik değerleri.

\begin{tabular}{lcccc}
\hline & Cinsiyet & $\mathbf{N}$ & $\bar{X}$ & $\mathbf{S}$ \\
\hline Zaman Planlama & Erkek & 132 & 3.23 & .58 \\
& Kadın & 61 & 3.36 & .55 \\
\hline Zaman Tutumları & Erkek & 132 & 3.43 & .45 \\
& Kadın & 61 & 3.44 & .53 \\
\hline Zaman Harcattırıcılar & Erkek & 132 & 3.39 & .75 \\
& Kadın & 61 & 3.66 & .62 \\
\hline Genel Ortalama & Erkek & 132 & 3.30 & .41 \\
& Kadın & 61 & 3.43 & .41 \\
\hline
\end{tabular}


Çalışmaya katılan öğrencilerin öğrenim gördükleri bölümlere göre Zaman Yönetimi alt boyut ve toplam puan ortalamaları Tablo 3'de verilmiştir.

Tablo 3. Katılımcıların bölümlerine göre Zaman Yönetimi alt boyutları ve toplam puan ortalamalarına ait betimsel istatistik değerleri.

\begin{tabular}{llccc}
\hline & Bölüm & $\mathbf{N}$ & $\bar{X}$ & Sd \\
\hline Zaman Planlaması & Rekreasyon & 69 & 3.32 & .58 \\
& Bed. Ĕg. Sp. Öğr. & 60 & 3.35 & .58 \\
& Antrenörlük & 64 & 3.14 & .55 \\
& Toplam & 193 & 3.27 & .57 \\
\hline Zaman Tutumları & Rekreasyon & 69 & 3.36 & .50 \\
& Bed. Ĕg. Sp. Öğr. & 60 & 3.46 & .42 \\
& Antrenörlük & 64 & 3.50 & .49 \\
& Toplam & 193 & 3.44 & .48 \\
\hline Zaman Harcattırıcılar & Rekreasyon & 69 & 3.51 & .64 \\
& Bed. Ĕg. Sp. Öğr. & 60 & 3.50 & .79 \\
& Antrenörlük & 64 & 3.41 & .73 \\
& Toplam & 193 & 3.47 & .72 \\
\hline Genel Toplam & Rekreasyon & 69 & 3.36 & .43 \\
& Bed. Eğ. Sp. Öğr. & 60 & 3.40 & .40 \\
& Antrenörlük & 64 & 3.27 & .39 \\
\hline
\end{tabular}

Yapılan analiz sonuçlarına göre; Beden Eğitimi ve Spor Öğretmenliği bölümünde öğrenim gören öğrencilerin Zaman Planlaması puanları, Rekreasyon ve Antrenörlük bölümüne göre daha yüksek çıktığı görülmektedir. Zaman Tutumları puanlarına bakıldığında puanların en yüksekten düşüğe doğru Antrenörlük, Beden Eğitimi ve Spor Öğretmenliği ve Rekreasyon bölümleri şeklinde sıralandığı görülmüştür. Zaman Harcattırıcılar puanlarına bakıldığında, Antrenörlük bölümünün diğer bölümlerden düşük puana sahip olduğu tespit edilmiştir. Genel toplamda ise en yüksek puanın Beden Eğitimi ve Spor Öğretmenliği Bölüme ait olduğu daha sonra sırasıyla Rekreasyon ve Antrenörlük olarak sıralandığı görülmektedir.

Katılımcıların öğrenim gördükleri bölüme göre, Zaman Yönetimi alt boyutları ve toplam puan ortalamaları arasında fark olup olmadığını tespit etmek amacı ile yapılan tek yönlü ANOVA sonuçlarına göre, SBTYO'da öğrenim gören öğrencilerin öğrenim gördükleri bölüm açısından Zaman Planlama [F ${ }_{(2-189)}=1.81, p>$.05], Zaman Tutumları [F $(2-$ $\left.{ }_{189}=.90, p>.05\right]$, Zaman Harcattırıcıları $\left[\mathrm{F}_{(2-189)}=.32, p>.05\right]$ alt boyutları ve genel toplam puanları arasında $\left[\mathrm{F}_{(2-189)}=1.13\right.$, p>.05] anlamlı bir fark olmadığı görülmüştür.

Çalışmaya katılan öğrencilerin öğrenim gördükleri sınıfa göre Zaman Yönetimi alt boyut ve toplam puan ortalamaları Tablo 4'de verilmiştir.

Tablo 4 incelendiğinde Zaman Planlaması ortalama puanlarının yüksekten düşüğe doğru 4., 3., 1. ve 2. sınıflar şeklinde sıralandığı görülmektedir. Zaman tutum puanlarına bakıldığında ise en yüksek puanın 1. sınıf öğrencilerinde olduğu, daha sonra da sırası ile 4., 3. ve 2. sınıflar şeklinde devam etmektedir. Zaman harcatıcılarda ise en yüksek puanların 1. ve 3. sınıflarda olduğu daha sonra sırasıyla 2. ve 4. sınıfların olduğu bulunmuştur. Genel toplamda ise bütün sınıfların birbirine çok yakın puana sahip olduğu görülmüştür.

Örneklem grubunun öğrenim gördükleri sınıflara göre Zaman Yönetimi alt boyutları ve toplam puan ortalamaları arasında fark olup olmadığını tespit etmek amacı ile yapılan tek yönlü ANOVA sonuçları göre SBTYO'da öğrenim gören öğrencilerin sınıflara göre, Zaman Planlaması $\left[F_{(3-209)}=.58, p>.05\right]$, Zaman Harcattırıcılar $\left[F_{(3-209)}=2.18\right.$, p>.05] alt boyutu ve genel toplam puanları arasında anlamlı bir farklılık görülmemektedir. Spor bilimleri öğrencilerinin, sınıflara göre Zaman Tutumları puanları arasında ise istatistiksel olarak anlamlı bir farklılık olduğu tespit edilmiştir $\left[F_{(3-189)}=4.32, p<.05\right]$. Bu farkın hangi sınıflar arasında olduğunu bulmak amacıyla yapılan Scheffe testinin sonuçlarına göre, 1. sınıf öğrencilerinin $(\bar{X}=3.54, S d=.53)$ Zaman Tutum alt boyutundan aldıkları puanın 2. sınıf öğrencilerinden $(\bar{X}=3.27, S S=.40)$ daha yüksek olduğu saptanmıştır. 
Tablo 4. Katılımcıların sınıflara göre Zaman Yönetimi alt boyutları ve toplam puan ortalamalarına ait betimsel istatistik değerleri.

\begin{tabular}{lllll}
\hline & Sınıf & N & $\bar{X}$ & Sd \\
\hline Zaman Planlaması & 1 & 83 & 3.28 & .61 \\
& 2 & 45 & 3.18 & .62 \\
& 3 & 36 & 3.28 & .47 \\
\hline Zaman Tutumları & 4 & 49 & 3.34 & .56 \\
& Toplam & 193 & 3.26 & .57 \\
\hline Zaman Harcattırıcılar & 1 & 83 & 3.59 & .52 \\
& 2 & 45 & 3.27 & .40 \\
& 3 & 36 & 3.36 & .47 \\
& 4 & 49 & 3.45 & .43 \\
& Toplam & 193 & 3.44 & .48 \\
\hline Genel Toplam & 1 & 83 & 3.60 & .66 \\
& 2 & 45 & 3.41 & .75 \\
& 3 & 36 & 3.57 & .72 \\
& 4 & 49 & 3.30 & .72 \\
& Toplam & 193 & 3.47 & .72 \\
\hline
\end{tabular}

\section{TARTIŞMA ve SONUÇ}

Bu araştırmanın amacı Spor Bilimleri Bölümlerinde öğrenim gören öğrencilerin zaman yönetimi davranışlarının, "Zaman Planlaması, Zaman Tutumları ve Zaman Harcattırıcılar" alt boyutlarında; cinsiyetlerine, eğitim gördükleri bölümlerine ve öğrenim gördükleri sınıflarına göre değişiklik gösterip göstermediğini incelemektir.

Araştırmada, Spor Bilimlerinde öğrenim gören öğrencilerin cinsiyet bakımından zaman yönetimi davranışları arasında fark olup olmadığı incelenmiş; çıkan sonuçlara göre, kadın ve erkek öğrenciler arasındaki farkın kadın öğrenciler lehine olduğu tespit edilmiştir. Kadın öğrencilerin zaman yönetimlerinin erkek öğrencilere göre daha iyi olmasının sebebi olarak kadınların toplumsal yapı gereği (aile içi görevler, okul hayatı, iş hayatı vb.) daha planlı ve düzenli yaşamaları gerektiğinden kaynaklanabileceği düşünülmektedir. Üniversite öğrencilerinin zaman yönetimi davranışları ve diğer parametreler ile olan ilişkisini inceleyen bazı çalışmaların sonuçları da bu çalışmanın sonucu ile paralellik gösterir şekilde, zaman yönetimi becerileri açısından, kadın öğrencilerin erkek öğrencilere oranla daha başarılı olduğunu göstermektedir $(12,16,17)$.

Bir diğer alt problemde, Spor Bilimlerinde öğrenim gören öğrencilerin öğrenim gördüğü bölüm açısından zaman yönetimi davranışları arasındaki fark incelenmiş; araştırmaya katılan öğrencilerin bölümlere göre ZYE'nin alt boyutları olan Zaman Planlaması, Zaman Tutumları, Zaman Harcattırıcılar ve toplam puan ortalamalarına göre anlamlı bir fark bulunmamıştır. Üniversite öğrencilerinin zaman yönetimi beceri düzeylerini ve bu becerilerin akademik başarı üzerine etkisini araştıran bir çalışmada, zaman yönetimi ile öğrencilerin öğrenim gördükleri fakülteye göre değişiklik göstermediği şeklinde benzer bir sonuç bulunmuştur (9).

Diğer alt problemde ise, Spor Bilimlerinde öğrenim gören öğrencilerin öğrenim gördükleri sınıf bakımından zaman yönetimi davranışları arasında fark olup olmadığı araştırılmış, alt boyutlardan Zaman Tutumu dışında diğer alt boyutlarda ve toplam puan ortalamalarında fark bulunamamıştır. Zaman tutumu alt boyutundaki farkın ise 1 . ve 2 . sınıf öğrenciler arasında 1. sınıf öğrenciler lehine olduğu tespit edilmiştir. Diğer boyutlarda anlamlı bir farklılık bulunmamasına karşın, ortalama puanlara bakıldığında, 1. sınıf öğrencilerinin ZYE'nin tüm alt boyutlarından ve toplam puanlarından aldıkları puanların diğer sınıf öğrencilerinden yüksek olduğu görülmektedir. Bunun nedeni üniversite yaşamlarının ilk yılında kendilerini meşgul edecek yeni derslerin olması, arkadaşlık ve sosyal çevrenin henüz gelişmemiş olması ve yeni bir ortama gelmelerinin verdiği tedirginlikle dikkatlerinin büyük çoğunluğunun okula veriliyor olması olabilir.

Bu çalışmada, sadece zaman tutum alt boyutunda 1. sınıflar lehine anlamlı bir farklılık bulunurken, aksine üniversite öğrencileri ile yapınla diğer bir çalışmada öğrencilerin öğrenim gördükleri sınıf ve yaşadıkları yer değişkenine göre anlamlı farklılık bulunamamıştır (9). Buna karşılık, diğer bir çalışmada ise üniversite öğrencilerinin ders çalışma becerileri incelenmiş ve son sınıf öğrencilerinin ders çalışma ve zaman yönetimi becerileri, birinci sınıflara göre daha 
yüksek olduğu bulunmuştur (16). Yine benzer bir çalışmada 25 yaş üstü üniversite öğrencilerinin 21 yaş altı ve 21-25 yaş arası üniversite öğrencilerine oranla daha etkili zaman yönetimi becerilerine sahip olduğu bulunmuştur (17). Başak ve arkadaşlarının (11) Hemşirelik Yüksek Okulu öğrencileri ile yapmış oldukları çalışmada, öğrencilerin yaşı arttıkça zamanı daha iyi yönettiği saptanmıştır. Yukarıda bahsedilen çalışmalarda bulunan sonuçlar bu çalışmanın bulguları ile paralellik göstermemektedirler.

Sonuç olarak, spor bilimlerinde öğrenim gören bireylerin cinsiyetlerine göre kadın öğrencilerin zaman yönetimi becerilerinin daha yüksek olduğu, bölümlerine göre zaman yönetimi becerileri arasında anlamlı bir farklılık olmadığı, sınıflarına göre ise, 1. sınıf öğrencilerinin zaman tutumları alt boyutunda diğer sınıflara göre anlamlı bir farklılık oluştuğu görülmektedir.

Spor Bilimleri öğrencilerinin gerek öğretmen, gerek rekreasyon uzmanı ve gerek antrenör olarak, zaman yönetimi becerisi yüksek olması beklenen kişiler olacağından, bulunan sonuçların çok önemli olduğu düşünülmektedir. Çıkan sonuç doğrultusunda, özellikle alan yazın ile karşılaştırıldığında meslek hayatına atılacak olan son sınıf öğrencilerine zaman yönetimi konusunda eğitimler verilmesi gerektiği ortaya çıkmaktadır. Çalışmaya başka üniversitelerin de eklenmesiyle örneklem geliştirilebilir. Ayrıca deneysel bir çalışma planlanarak; zaman yönetimi ile ilgili derslerin verilmesinin, zaman yönetimi becerisine etkisi incelenebilir.

\section{KAYNAKLAR}

1. Özgen H. ve Doğan S., "Zaman Yönetiminde Yeni Yönetim ve Organizasyon Yaklaşımları", Standard Dergisi, 36,425, s. 136-145, 1997.

2. Erdem R. ve Kocabaş İ., "Yönetici Adayı Öğretmenlerin Kişisel Zaman Yönetimi Davranışları", Fırat Üniversitesi Sosyal Bilimler Dergisi, 13, 2, s. 203-210, 2003.

3. Erdem R. ve Kaya S., "Zaman Yönetimi”, Çağdaş Yerel Yönetimler Dergisi, Todaie Yayınları, Ankara, 7, 2, s. 99-120, 1998.

4. Karaküçük S., Rekreasyon Boş Zamanları Değerlendirme, Gazi Kitabevi, s.1-13, Ankara, 2007.

5. Öktem M. K., "Zaman Yönetimi: Örgütsel Etkinliği Arttırmada Zaman Faktöründen Yararlanılması", Amme İdaresi Dergisi, 26,1, s. 217-237, 1993.

6. Keenan, K., Yöneticinin Kılavuzu, Zamanı Doğru Kullanma, Çev: E. Koparan, Remzi Kitabevi, İstanbul, s. $63,1996$.

7. Örücü E., Tikici M. ve Kanbur A., "Farklı Sektörlerde Faaliyetlerini Sürdüren İşletmelerde Zaman Yönetimi Üzerine Amprik Bir Araştırma, Bursa İli Örneği”, Elektronik Sosyal Bilimler Dergisi, 6, 20, s.156-176, 2007.

8. Koch C. J., Kleinmann M., "A Stitch in Time Saves Nine: Behavioural Decision Making Explanations For Time Management Problems", European Journal of Work and Organizational Psychology, 11, 2, p. 199-217, 2002.

9. İşcan S. Pamukkale Üniversitesi Öğrencilerinin Zaman Yönetimi Becerilerinin Akademik Başarıları Üzerindeki Etkisi, (Yayınlanmamış Yüksek Lisans Tezi) Pamukkale Üniversitesi Eğitim Fakültesi, Denizli, 2008.

10. Dikmetaş E., Erdem R. ve Pirinçci E., "Üniversite Öğrencilerinin Zaman Yönetimi Davranışları ve Bu Davranışların Akademik Başarı İle İlişkisi”, Manas Üniversitesi Sosyal Bilimler Dergisi, 10, s. 175-189, 2004.

11. Başak T., Uzun Ş., Arslan F., "Hemşirelik Yüksekokulu Öğrencilerinin Zaman Yönetimi Becerileri”, TAF Prev Med Bull, 7, (5), p. 429-434, 2008

12. Macan, T. M., Shahani, C., Dipboye, R. L., \& Phillips, A. P., "College Students' Time Management: Correlations With Academic Performance And Stress", Journal of Educational Psychology, 82, p. 760-768, 1990.

13. Erdul, G., "Üniversite Öğrencilerinin Zaman Yönetimi Becerileri İle Kaygı Düzeyleri Arasındaki İlişki”, (Yayınlanmamış Yüksek Lisans Tezi). Uludağ Üniversitesi, Bursa, 2005.

14. Dinçay, H., Koçak, S. "Seçilmiş Üniversite Öğrencilerinin Zaman Yönetimi Becerileri ve Fiziksel Aktivite Düzeyleri Arasındaki İlişki", 11. Uluslararası Spor Bilimleri Kongre Kitapçığı, Antalya, Türkiye, s. 193, 2010.

15. Fidan, F., Latif H. ve Uçkun G., "Üniversite Öğrencileri Ne Yapıyor? Zaman Değerlendirme mi Zaman Geçirme mi? ( Sakarya üniversitesi Örneği)", http://www.isletme-finans.com, 2005, (22.05.2009).

16. Alay, S. ve Koçak, S., "Üniversite Öğrencilerinin Zaman Yönetimleri ile Akademik Başarıları Arasındaki İlişki", Kuram ve Uygulamada Eğitim Yönetimi, 35, s. 326-335, 2003.

17. Bay, E., Tuğluk, M. N. ve Gençdoğan, B., "Üniversite Öğrencilerinin Ders Çalışma Becerilerinin İncelenmesi." Elektronik Sosyal Bilimler Dergisi. 4, s. 94-105, 2005. (www.e.sosder.com),

18. Trueman, M., Hartley, J. A., "Comparison Between The Time-Management Skills and Academic Performance of Mature and Traditional-Entry University Students", Higher Education, 32(2), p. 199-215, 1996. 